\title{
Drug Utilization Study of Statin in Hemorrhagic Stroke
}

\author{
Nailis Syifa $^{1}{ }^{*}$, Cici Dwi ${ }^{1}$ and Didik Hasmono ${ }^{2}$ \\ ${ }^{1}$ Pharmacy department, University of Muhammadiyah Malang, Indonesia \\ Jalan Bendungan Sutami 188 A, Kota Malang, Jawa Timur 65145 \\ ${ }^{2}$ Faculty of Pharmacy, University of Airlangga, Indonesia \\ Jalan Dharmawangsa No.4-6, Airlangga, Gubeng, Kota Surabaya, Jawa Timur 60286 \\ *Correspondence author: naily_sifa@yahoo.com
}

\begin{abstract}
Background: Hemorrhagic stroke is a neurologic injury resulting in significant morbidity and mortality. Some studies noted an increasing risk of hemorrhagic stroke in patients receiving statin. However, growing evidence have demonstrated the neuroprotective effects of statin in hemorrhagic stroke. Objectives: To determine the pattern of statins use in hemorrhagic stroke. Methods: Observational retrospective study using Patient Medical Records from January 2015 - December 2016. Results and Conclusion: We obtained 15 patients (6.5\%) who received statins therapy from 230 total patients with hemorrhagic stroke. Statins used are atorvastatin in 13 patients (87\%) and simvastatin in 2 patients (13\%). The dosage of atorvastatin was $20 \mathrm{mg}$ orally, once daily, and the dosage of simvastatin was $20 \mathrm{mg}$ orally, once daily. All patients who received statins showed an improvement profile outcomes.
\end{abstract}

Keywords: Statin, Hemorrhagic Stroke, Retrospective

\section{INTRODUCTION}

Hemorrhagic stroke is associated with significant morbidity and mortality (Newsome, Casciere \& Jordan et al. 2015). In this type of stroke, the primary pathology is an area of bleeding causing direct damage to the brains tissue. There are primarily two different types of hemorrhagic strokes; subarachnoid hemorrhage (SAH) and intracerebral hemorrhage (ICH) (Gomes \& Wachsman 2013). Both ICH and SAH lead to poor prognosis and severe psychomotor disability (Kotlega et al. 2015).

Statins (3-hydroxy-3-methylglutaryl-coenzyme a reductase inhibitors) are known to reduce the risk of ischemic stroke among patients with history of ischemic stroke (Kotlega et al. 2015). In addition, statin uses during hospitalization for ischemic stroke has been found to be strongly associated with improved outcomes, and the cessation of statin uses has been associated with worsened outcomes (Flint et al. 2012). Ischemic stroke and hemorrhagic stroke (intracerebral hemorrhage $[\mathrm{ICH}]$ ) have different primary mechanisms, but they share many molecular mechanisms for secondary brain injury that may be influenced by statin uses (Aronowski \& Zhao 2011).

There are more emerging results of studies suggesting usefulness of these drugs in intracerebral hemorrhage (ICH) and subarachnoid hemorrhage (SAH) (Kotlega et al. 2015). Statins display several independent effects of cholesterol reduction, like GTPases regulation, through which a number of pathways could be modulated and lead to a neuro protective action (Perez et al. 2015). 


\section{METHOD}

We retrospectively analyzed data from patient medical records in Sidoarjo Hospital from January 2015 until December 2016. All patients with stroke hemorrhagic were obtained. The eligible patients were patients who received statin therapy at least 3 days using. Patients information, including sex, age, medication use, dosage, and clinical outcome were determined.

\section{RESULT AND DISCUSSION}

We obtained 15 patients $(6.5 \%)$ received statins therapy from 230 total patients with hemorrhagic stroke. The different types of hemorrhagic stroke showed 14 patients (93\%) intracerebral hemorrhagic and 1 patient (7\%) subarachnoid hemorrhage. Sex characteristics showed 8 patients $(53 \%)$ are male and 7 patients $(47 \%)$ are female. While age distributions showed that all of hemorrhagic stroke patients were above 40 years. Epidemiology study by Joseph et al showed that the evidence of intracerebral hemorrhagic is more than twice as common as subarachnoid hemorrhage (Broderick et al. 1993). It also showed that the incidence of intracerebral hemorrhage increases with advance age (Broderick et al. 1993; Ariesen et al. 2003; An et al. 2017).

Table 1 Risk Factor of Stroke Hemorrhagic

\begin{tabular}{cc}
\hline Risk Factor & Percentage (\%) \\
\hline Hypertension & 48 \\
Diabetes Mellitus & 7 \\
Dyslipidemia & 3 \\
Smoking & 14 \\
Dietary & 28 \\
\hline Total & 100 \\
\hline
\end{tabular}

According to Ariesen et al, hypertension, diabetes mellitus, dyslipidemia, and smoking are the risk factor of both intracerebral hemorrhagic and ischemic stroke. Obvious risk factor on ICH is hypertension. Therefore, more attention should be given to modifiable risk factor hypertension to reduce the risk of ICH (Ariesen et al. 2013). Dyslipidemia is one of the risk factors in hemorrhagic stroke. Other studies explained that because the risk factors for nonlobar intracerebral hemorrhage are similar to those for atherosclerotic events (including smoking, hypertension, obesity, and diabetes mellitus), clinicians should continue to use treatment algorithms that base the initiation of statins on each individual's global risk for cardiovascular events (Hackam et al. 2011).

Table-2. Profile Pattern of Statin in hemorrhage Stroke

\begin{tabular}{lll}
\hline Statin & Dosage & Percentage (\%) \\
\hline Atorvastatin & $1 \times 20 \mathrm{mg}$ PO & 87 \\
Simvastsatin & $1 \times 20 \mathrm{mg} \mathrm{PO}$ & 13 \\
\hline \multicolumn{2}{c}{ Total } & 100 \\
\hline
\end{tabular}

Statins that were used in this study are simvastatin (13\%) and atorvastatin (87\%). Simvastatin is a fermentation-derived natural statin, and atorvastatin is a synthetic statin. They have different lipid solubility profiles, with simvastatin being more lipophilic (Furberg 1999). Statin penetration across the blood-brain barrier and into the cerebral cortex is directly related to the lipophilic properties of each statin (Wood et al. 2010). 
In a previous study, 10-year nationwide follow-up cohort study of newly diagnosed ICH patients receiving statin therapy demonstrated that users of hydrophilic statins had a significantly lower risk of recurrent ICH than did users of lipophilic statins. Additionally, the intensity of statin use had no significant relationship with recurrent ICH or other secondary adverse outcomes. Additional prospective randomized clinical trials are required to confirm the favorable effects of hydrophilic statin therapy in ICH patients (Tai, Lin \& Lee et al. 2016). According to study in animal, simvastatin and atorvastatin treatment for 1 week after ICH significantly improved neurological outcome and reduced hematoma volume and tissue loss at 4 weeks. Simvastatin was equal or slightly more effective than atorvastatin. The reduction of tissue loss with statin treatment of ICH was associated with increased neurogenesis. These findings also suggest that MRI is a reliable method to measure ICH volume and the volume of tissue loss after experimental ICH and may be useful for evaluating the efficacy of therapeutic interventions (Karki, Knight \& Han 2015).

Another study "The Stroke Prevention by Aggressive Reduction in Cholesterol Levels" suggested that an increased risk of ICH in patients treated with high-dose atorvastatin, especially in those patients with a previous hemorrhagic stroke, in men, and in those with increased age. Patients with stage II of hypertension before the ICH also have an increased risk (Goldstein et al. 2008). However, the existence of such risk was refuted by 2 larger meta-analyses (Hackam, et al. 2011). In a further meta-analysis from 2014, Lei et al included 1652 subjects exposed to statin and 5309 non users who had an ICH. With an interesting statistical performance, they suggested that there is no evidence to speculate that previous statin use at least increases the mortality among ICH patients (Lei et al. 2014). The possible benefit of statin use in ICH is far away from the mere effect on the cholesterol production. Statins regulate small GTPases that are widely distributed in the cell and are indispensable for the regulation of several pathways. The regulation of nitric oxide synthases, growth factors (eg, angiogenesis, neurogenesis), immune cells, and cytokines and free radical scavengers are an example of the functions regulated by GTPases (Perez et al. 2015).

Table 3 Drug Therapy Profile in Stroke Hemorrhagic Patients

\begin{tabular}{|c|c|c|c|}
\hline Therapy & Classification & Medication & Number of Patients \\
\hline \multirow[t]{9}{*}{ Antihypertensive } & Calcium Channel & Nicardipine & 1 \\
\hline & Blocker & Nimodipine & 2 \\
\hline & & Amlodipine & 5 \\
\hline & Diuretic & Furosemide & 2 \\
\hline & & Spironolactone & 1 \\
\hline & B-blocker & Bisoprolol & 3 \\
\hline & $\mathrm{ARB}$ & Valsartan & 4 \\
\hline & & Candesartan & 3 \\
\hline & Total & & 21 \\
\hline \multirow[t]{2}{*}{ Osmoterapi } & Diuretic & Mannitol & 8 \\
\hline & Total & & 8 \\
\hline \multirow[t]{3}{*}{ Neuroprotector } & & Citicolin & 14 \\
\hline & & Piracetam & 2 \\
\hline & Total & & 16 \\
\hline \multirow[t]{2}{*}{ Antifibrinolitic } & & Tranexamic Acid & 2 \\
\hline & Total & & 2 \\
\hline \multirow[t]{2}{*}{$\begin{array}{l}\text { Anticoagulant } \\
\text { antagonist }\end{array}$} & & Vit. K & 1 \\
\hline & Total & & 1 \\
\hline
\end{tabular}


According to this study outcome profile when patient out of the hospital were showed $100 \%$ improvement outcome. The current evidence suggests that continuing statin after ICH onset might be highly related to improve the outcome of patients with ICH. Despite of this strong suggestion, randomized controlled trials should be performed to further investigate this association (Perez et al. 2015). Furthermore, evidence suggests that statin therapy should be continued to avoid the adverse effects of abrupt discontinuation in patients with both ICH and aSAH. Data published since the last aSAH guidelines suggest that DINDs are not significantly reduced by statin use. Definitive evidence is still awaited regarding the effect of statin therapy on functional outcomes after ICH and aSAH; however, existing data suggest overall safety and possibly improved outcomes with continuation of statin therapy for vascular indications. Thus for those patients with vascular indications and the absence of a contraindication, statin therapy should be continued during admission for hemorrhagic stroke (Newsome et al. 2015). Other study showed that early statin group patients with acute ICH did not have a higher recurrent risk of ICH and might have lower all-cause mortality during follow-up. Statin therapy might be beneficial for patients with ICH (Chen et al. 2015). In-hospital statin use in ICH patients is associated with better functional outcome and lower mortality at 3 months and 1 year (Pan et al. 2014).

\section{CONCLUSION}

We obtained 15 patients $(6.5 \%)$ received statins therapy from 230 total patients with hemorrhagic stroke. Statins that are used atorvastatin in 13 patients (87\%) and simvastatin in 2 patients (13\%). The dosage of atorvastatin was $20 \mathrm{mg}$ orally, once daily, and the dosage of simvastatin was $20 \mathrm{mg}$ orally, once daily. All patients who received statins showed improvement profile outcomes.

\section{ACKNOWLEDGEMENT}

We are thankful to Director of Sidoarjo Hospital for giving permission to undertake the data. We are also grateful to Staff at Sidoarjo Hospital, Indonesia

\section{ETHICAL APPROVAL}

This study was approved by the Ethic Comission University of Muhammadiyah Malang.

\section{REFERENCES}

Ariesen, M.J., Claus, S.P., Rinkel, G.J.E., et al. 2003. Risk Factors for Intracerebral Hemorrhage in the General Population : A Systematic Review. Stroke: AHA Journals.

Aronowski, J., and Zhao, X., 2011. Molecular Patophisiology of Cerebral Hemorrhage : Secondary Brain injury. Stroke; 42:1781-1786.An, S.J., Kim, T.J., and Yoon, B.W., 2017. Epidemiology, Risk Factors, and Clinical Features of Intracerebral Hemorrhage: An Update. Journal of Stroke; 19(1): 3-10.

Broderick, J.P., Brott, T., Tomsick, T., et al. 1993. Intracerebral Hemorrhage More Than Twice As Common As Subarachnoid Hemorrhage. J. Neurosurg Vol.78.

Chen, P.S., Cheng, C.L., Chang, Y.C., et al. 2015. Early Statin Therapy in Patients with Acute Intracerebral Hemorrhage without Prior Statin. European Journal of Neurology: 1-8

Furberg, C. D., 1999. Natural Statins and Stroke Risk. Circulation; 99:185-188. 
Flint, A.C., Kamel, H., Navi, B.B., et al. 2012 Statin Use during Ischemic Stroke Hospitalization is Strongly Associated with Improved Poststroke Survival. Stroke: 43(1):147-154.

Goldstein, L.B. Amarenco, P., Szarek, M., et al. 2008. Hemorrhagic Stroke in the Stroke Prevention by Aggresive Reduction in Cholesterol Level Study.

Gomes, J., and Wachsman, A.M., 2013. Handbook of Clinical Nutrition and Stroke. Springer Science.

Hackam, D.G., Woodward, M., Newby, K., et al. 2011. Statins and Intracerebral Hemorrhage: Collaborative Systematic Review and Meta Analysis. Circ.ahajournals.org.

Karki, K., Knight, R.A., Han, Y., 2015. Simvastatin and Atorvastatin Improve Neurological Outcome After Experimental Intracerebral Hemorrhage. AHAJournals

Kotlega, D., Masztawelicz, M., Ciecwiez, S., and Nowacki, P., 2015. Potential Role of Statins in the Intracerebral Hemorrhage and Subarachnoid Hemorrhage. Elsevier: Science Direct.

Lei, C., Wu, B., Liu, M., and Chen, Y., 2014. Association between Statin Use and Intracerebral Hemorrhage: a Systematic Review and Meta Analysis

Newsome, A.S., Casciere, B.C., Jordan, J.D., et al. 2015. The Role of Statin Therapy in Hemorrhagic Stroke. Pharmacotherapy- The Journal of Human Pharmacology and Drug Therapy Volume issue 12.

Pan, Y. S., Jing, J., Wang, Y. L., et al., 2014. Use of Statin During Hospitalization Improves the Outcome After Intracerebral Hemorrhage. CNS Neuroscience \& Therapeutics, 548-555.

Perez, J.H.T., Yildiz, O.C., Schneider, T., and Nimsky, C. 2015. Meta-analysis of Statin Use for the Acute Therapy of Spontaneous Intracerebral Hemorrhage. Journal of Stroke and Cerebrovascular Disease : pp. 1-6.

Tai, S.Y., Lin, F.C., Lee, C.Y., et al., 2016. Statin Use after Intracerebral Hemorrhage: a 10-year Nationwide Cohort Study. Brain and Behavior, e00487.

Wood, W. G., Eckert, G. P., Igbavboa, U., and Muller, W. E., 2010. Statins and Neuroprotection. A Prescription to Move the Field Forward. Ann. N.Y.Acad. Sci. 